\title{
SELECTED ASPECTS OF ANALYSES OF FAILURE RATES OF ACTIVE SAFETY SYSTEMS IN BUSES
}

The article outlines the methodology of statistical analysis of failure rate of active safety systems in buses. The theoretical discussion is illustrated with calculations carried out on the basis of empirical data covering a four-year period of operation of selected models of buses at the Motor Transport Company "Wschod“ plc in Lublin (Poland). It was found that the distribution of distances travelled by the analyzed vehicles between successive repairs can be approximated by an exponential distribution.

Keywords: Motor transport, failure rate, active safety systems.

\section{Introduction}

Buses, as means of motor transport which use public roads and are intended for transporting people, must meet stringent technical requirements specified by the relevant legal provisions. These regulations set out, among others, the requirements for the equipment of such vehicles and their systems designed to ensure safety (active and passive) of passengers and other road users (In Poland, these issues are governed by regulations of the Minister of Transport and Maritime Economy [1].) The concept of the car's active safety represents all activities the purpose of which is to reduce to a minimum the likelihood of a collision or accident while driving [2]. This concept also includes mechanisms and devices enabling the driver to actively counteract and prevent the occurrence of a traffic collision involving the vehicle he or she is driving. In addition to the skills, experience and the psychophysical state of the driver, a key factor deciding the level of active safety is the technical condition of the vehicle [3]. The efficiency of a vehicle's safety systems should be maintained throughout its operating life, under all weather conditions and in all traffic situations.

Basically, active safety of the car is affected by the technical condition of all structural systems that make up its structure: powertrain, chassis, steering, braking system, electrical system, suspension, etc. However, from the point of view of the essential purpose of a system, the so-called automotive active safety systems primarily include the braking, steering and suspension systems [4] and [5]. The braking system dissipates excess mechanical energy obtained by the vehicle as a result of acceleration or climbing a hill. The steering system, in addition to its primary function of allowing the driver to change the path of travel, must enable safe execution of these manoeuvres also at high speeds. The suspension system, in addition to improving the comfort of the driver and passengers, is also responsible for safe manoeuvring. Any defects of component parts of the systems listed above result in dispatching the vehicle for repair. This article discusses selected aspects of analyses of the failure rate of active safety systems in buses. The discussion is illustrated with calculations carried out for selected makes of buses operated in the years 2008-2012 at the Motor Transport Company "Wschod" plc. (PKS "Wschod") based in Lublin (Poland).

\section{Characteristics of common failures of active safety systems in buses}

A bus is a motor vehicle used for the transport of persons which has a seating capacity of at least 10 (including the driver's seat). In addition to seats, buses (especially public buses) may also offer standing room for passengers. The seating and standing capacity is strictly defined for each bus type produced and it must not be exceeded for safety reasons. The total seating and standing capacity is limited by the vehicle's gross mass and its dimensions [6]. Contemporarily manufactured buses are divided according to their gross mass and dimensions into vans, minibuses, midibuses, maxibuses and megabuses. An estimated relationship between the class of a bus and the maximum number of passengers it can carry is shown in Table 1.

\footnotetext{
* ${ }^{1}$ Pawel Drozdziel, ${ }^{2}$ Leszek Krzywonos, ${ }^{3}$ Radovan Madlenak, ${ }^{1}$ Iwona Rybicka

'Institute of Transport, Combustion Engines and Ecology, Faculty of Mechanical Engineering, Lublin University of Technology, Poland, E-mail: p.drozdziel@pollub.pl

${ }^{2}$ Department of Machine Design, Faculty of Mechanical Engineering, Lublin University of Technology, Poland

${ }^{3}$ Department of Communications, Faculty of Operation and Economics of Transport and Communications, University of Zilina, Slovakia
} 
Number of passengers on buses of particular classes [7] Table 1

\begin{tabular}{|c|c|c|c|}
\hline Class of buses & $\begin{array}{c}\text { Number of passengers } \\
{[-]}\end{array}$ & $\begin{array}{c}\text { Gross vehicle } \\
\text { mass } \\
{[\mathrm{t}]}\end{array}$ & $\begin{array}{c}\text { Bus length } \\
{[\mathrm{m}]}\end{array}$ \\
\hline MICRO & $9-16$ & below 3.5 & below 6 \\
\hline MINI & $17-49$ & $6-9$ & $6-8$ \\
\hline MIDI & up to 75 & $12-15$ & $9-10$ \\
\hline MAXI & up to 120 & $16-19$ & $11-12$ \\
\hline MEGA & above 120 & $24-28$ & $13-18$ \\
\hline
\end{tabular}

Types of failures occurring in active safety systems of buses (braking, steering and suspension systems) depend both on the design solutions applied, as well as the operating conditions of those vehicles (state of road infrastructure, traffic, number of stops on the route, etc.). General analyses show that in braking systems, wear affects friction elements (pads, discs, shoes and brake drums) as well as actuators and safety valves. Also registered are failures of wear sensors of friction elements as well as components of electronic circuits of anti-lock systems and power booster systems [8]. Steering systems of buses are prone to failures of kinematic pairs in the connections of lever elements (rods and the steering column) as well as components of power steering systems. The suspension systems and the chassis are mainly affected by wear to shock-absorbing elements as well as kinematic pairs of lever elements, which operate under friction. Due to the large gross vehicle mass and the need for frequent stopping at bus stops, wear of friction elements in braking systems should be the dominant type of wear in public transport buses operating in cities and districts.

\section{Outline of research methodology}

Failure rate is a physical parameter used in the theory of reliability, where it is defined as the number of object (system) failures per unit of time. Failure rate is a function of operating time. Its value is estimated by calculating the ratio of the number of failures occurring during a time interval to the length of this interval. In the case of failure rates of automotive components and assemblies, operating time can be expressed in two ways. It can either be measured in calendar units (number of days, months, years, etc.) or mileage, i.e. the number of kilometres travelled by the vehicle as registered by the odometer installed in it as standard equipment. This is so because the theory of reliability uses the concept of "generalized time".

The basic (empirically confirmed) qualitative model of changes in the failure rate of a population of engineering objects as a function of operating time is the so-called "bathtub" curve [9]. This curve consists of three periods: an initial decrease in failure rate associated with the break-in of components followed by a period of constant failure rate during the object's useful life, and concluding with a wear-out period with increasing failure rate. The lengths of these periods and failure rates recorded at particular moments in time depend on the types of objects or systems studied and the conditions in which they are used.

It is difficult, for economic and organizational reasons, to collect information about car failures occurring at longer time intervals. In principle, it is impossible to collect a sufficient number of data to perform statistical analyses using the planned experiment method. This is because such analyses require homogeneous populations of large numbers of objects. A practicable solution is to use databases created by large economic entities that deal with automotive diagnostics or have inspection stations designed for servicing their own fleets of vehicles [10].

In the case of inspection stations that provide services exclusively to external clients, it is impossible to monitor the performance of the vehicles diagnosed and repaired at the station over time (except when the diagnostic specialist has regular customers). Research material obtained from such entities is very comprehensive, yet very incomplete. The situation is different when an inspection station belongs to a transportation company and chiefly provides diagnostic services to its own fleet of vehicles. The information collected in maintenance databases of such companies is more accurate, though it usually covers a smaller number of diagnosed objects.

In Polish conditions, reliable bus failure data can be obtained from major passenger transport companies such as urban transport operators or road transport companies. However, each company records these data in an individual manner, tailored to their own needs. The differences are often so significant that it is impossible to compare the results of reliability analyses of transport systems of different companies with similar business activities. From the point of view of the methodology of failure rate research, it is also important that data collected by companies typically relate to repairs and can therefore cover cases of preventive replacement of non-failed components and delays of some repairs (when the failure is not detected at the time of occurrence). These types of events give the impression of accumulation of failures. However, considering the fact that the issues discussed here concern the safety of many people and as such are subject to sanctions for non-compliance, it can be assumed that repairs of failures of bus active safety systems are carried out immediately after they have occurred. Thus, the failure rates of the components of such systems can be estimated on the basis of the length of time intervals between consecutive repairs. In the present article, this parameter is referred to as distance between repairs.

The lengths of the time intervals between consecutive repairs of the failures of a test bus are characterized by random variation with an unknown probability distribution. This distribution can be identified using statistical tests which assess the goodness of fit of the empirical distribution to typical theoretical probability distributions and allow one to choose the best among them. The procedure for testing the goodness of fit of a given empirical distribution of distance between repairs of safety systems of 
an urban or an intercity public transport bus should start from checking its fit to the normal distribution. A normal distribution can be a mathematical model of the variation in distance between repairs when failures are varied and there is no noticeable dominant factor.

Currently, the most powerful statistical test for testing goodness of fit to the normal distribution is the Shapiro-Wilk test. If the hypothesis of goodness of fit to the normal distribution is rejected, the empirical distribution should be tested for goodness of fit to an exponential distribution. The Chi-Square $\left(\chi^{2}\right)$ or the Kolmogorov goodness of fit tests can be used for this purpose [11]. An exponential distribution is justifiably used when the failures have the character of a breakdown, i.e. when they appear as a result of the action of external causes which occur randomly and at a constant rate. In the case of a breakdown of bus active safety systems, this would entail the existence of a dominant type of failure. Rejection of the hypothesis of the goodness of fit of the empirical distribution to normal and exponential distributions paves the way for further comparisons with theoretical distributions, in which failure rate is not a constant function. In such cases, empirical data should be compared with selected probability distributions of the gamma distribution family.

\section{Sample analyses of the distributions of distance between successive repairs}

To illustrate the problem discussed, a statistical analysis of failure rates of safety system components was carried out for selected buses operated by the Motor Transport Company
"Wschod" plc. (PKS "Wschod"). PKS "Wschod" was established by consolidation of five state-owned enterprises in accordance with the decree of the governor of Lublin of 28 December 2006. It included motor transport companies with offices in five cities of the province of Lublin: Hrubieszow, Tomaszow Lubelski, Krasnystaw, Wlodawa and Lublin. The services provided by PKS "Wschod" include, among others, coach hire, maintenance and repair of motor vehicles and roadside assistance. Its major domain of activity is transport of passengers between districts (at distances of 50-60 km) and the provision of intercity and international bus services.

Data on bus failures were kindly provided by the company's management. For the purposes of the test, we analyzed failures of three Scania Irizar CENTURY buses operated in the Lublin branch in the period from July 2008 to October 2012. Scania Irizar CENTURY is a maxi class coach with a length of 12 meters, gross vehicle weight of 18 tonnes, and a seating capacity of 51. During the period discussed the buses ran on intercity lines. Table 2 shows identification data for the individual vehicles.

In the analyzed period, the buses travelled distances of $400,000 \mathrm{~km}$ (Table 2), which means that they were operated with a similar intensity. In all cases, similar numbers of repairs were recorded, resulting in similar mean failure rates for each bus. Years of manufacture of the buses and odometer readings for July 2008 show that the period for which the failure data were collected does not include mechanical run-in of the vehicles.

Table 3 shows basic descriptive statistics related to the distance between repairs of faults in the safety systems of the analyzed buses. In the cases considered, the empirical coefficient of variation (standard deviation of the sample divided by the arithmetic mean) oscillates around the value of 1 .

Basic data on the Scania Irizar CENTURY buses (data obtained from: PKS "Wschod" plc.)

Table 2

\begin{tabular}{|c|c|c|c|c|c|}
\hline Buses & Year of manufacture & $\begin{array}{c}\text { Odometer reading } \\
\text { July 2008 } \\
{[\mathrm{km}]}\end{array}$ & $\begin{array}{c}\text { Odometer reading } \\
\text { October 2012 } \\
{[\mathrm{km}]}\end{array}$ & $\begin{array}{c}\text { Bus's mileage } \\
{[\mathrm{km}]}\end{array}$ & $\begin{array}{c}\text { Documented number } \\
\text { of repairs } \\
{[-]}\end{array}$ \\
\hline Bus I & 2001 & 765928 & 1152895 & 386967 & 20 \\
\hline Bus II & 2002 & 725220 & 1154467 & 429247 & 18 \\
\hline Bus III & 2005 & 384422 & 842441 & 458019 & 19 \\
\hline
\end{tabular}

Descriptive statistics for the distance between successive repairs of safety system faults in Scania Irizar CENTURY coaches operated by PKS “Wschod” plc. in Lublin from July 2008 to October 2012 (Source: Authors' compilation of maintenance data provided by PKS "Wschod")

Table 3

\begin{tabular}{|c|c|c|c|c|c|}
\hline Buses & $\begin{array}{c}\text { Number of repairs } \\
{[-]}\end{array}$ & $\begin{array}{c}\text { Mean value } \\
{[\mathrm{km}]}\end{array}$ & $\begin{array}{c}\text { Minimum value } \\
{[\mathrm{km}]}\end{array}$ & $\begin{array}{c}\text { Maximum value } \\
{[\mathrm{km}]}\end{array}$ & $\begin{array}{c}\text { Standard deviation } \\
{[\mathrm{km}]}\end{array}$ \\
\hline Bus I & 20 & 19348 & 600 & 49092 & 16497 \\
\hline Bus II & 18 & 23847 & 1450 & 110470 & 26338 \\
\hline Bus III & 19 & 24106 & 1528 & 84483 & 20140 \\
\hline Buses I-III & 57 & 22355 & 600 & 110470 & 20935 \\
\hline
\end{tabular}


a)

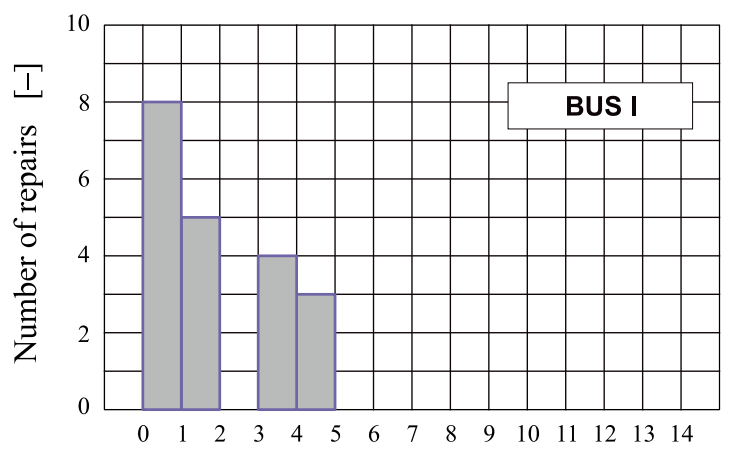

Distance between repairs $\left[10^{4} \mathrm{~km}\right]$

b)

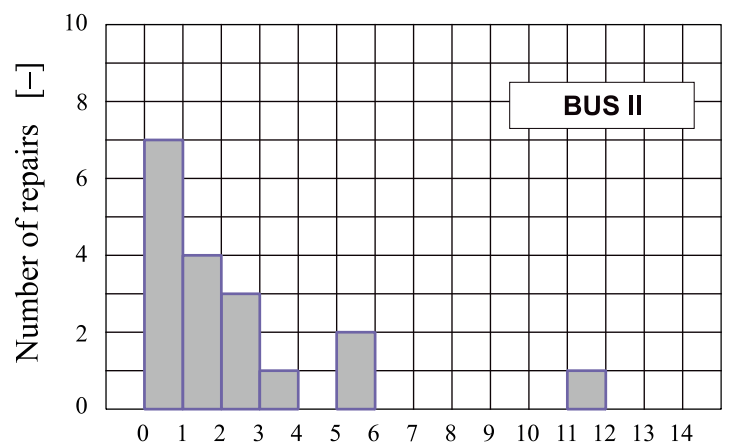

Distance between repairs $\quad\left[10^{4} \mathrm{~km}\right]$ c)

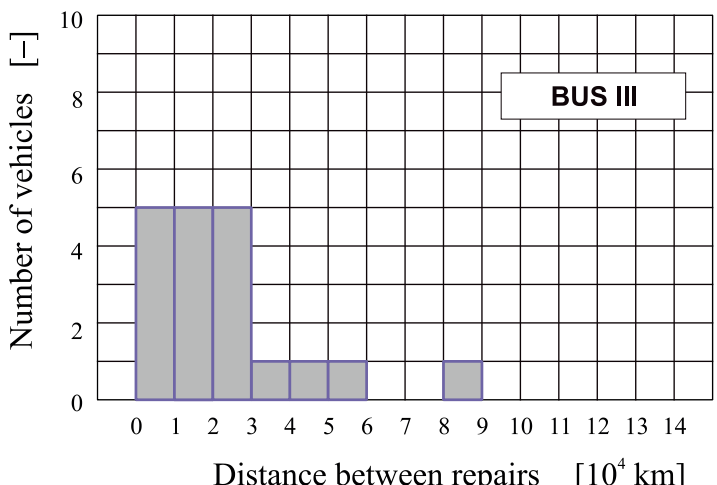

d)

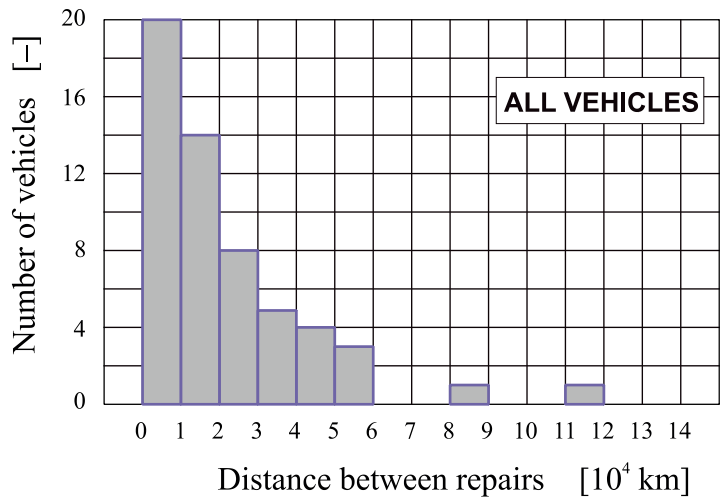

Fig. 1 Histograms of empirical distributions of distances between repairs of safety systems of Scania Irizar CENTURY buses operated by PKS "Wschod" plc. in Lublin in the period from July 2008 to October 2012; a) bus I, b) bus II, c) bus III, d) buses I-III (Source: Authors' compilation of maintenance data provided by PKS "Wschod")

Figure 1 shows histograms of empirical distributions of distances between repairs of safety systems of the analyzed buses. For easy comparison of sample sizes, the same widths of class intervals were used in all cases (both for the individual buses and the three buses analyzed together).
According to the procedure described in section 3 of this article, tests were carried out for goodness of fit of empirical distributions to the normal distribution. The results of the Shapiro-Wilk test are shown in Table 4 . They unequivocally show that at the level of significance $\alpha=0.05$, the hypotheses of

The results of the Shapiro-Wilk test for goodness of fit to the normal distribution of empirical distributions of distance between repairs of Scania Irizar CENTURY buses operated by PKS "Wschod" in the period from July 2008 to October 2012

(Source: Authors' compilation of maintenance data provided by PKS "Wschod")

\begin{tabular}{|c|c|c|c|c|c|}
\hline Buses & $\begin{array}{c}\text { Sample size } \\
\text { N } \\
{[-]}\end{array}$ & $\begin{array}{c}\text { Level of significance } \\
\alpha \\
{[-]}\end{array}$ & $\begin{array}{c}\text { Value of Shapiro-Wilk } \\
\text { statistic } \\
{[-]}\end{array}$ & $\begin{array}{c}\text { p-value } \\
{[-]}\end{array}$ \\
\hline Bus I & 20 & 0.05 & 0.877 & 0.016 & 0.000 \\
\hline Bus II & 18 & 005 & 0.740 & 0.003 & NO \\
\hline Bus III & 19 & 005 & 0.825 & 0.000 & NO \\
\hline Buses I-III & 57 & 005 & 0.827 & NO \\
\hline
\end{tabular}


The results of the $\chi^{2}$ test for goodness of fit to the exponential distribution of empirical distributions of distance between repairs of Scania Irizar CENTURY buses operated by PKS "Wschod” in the period from July 2008 to October 2012

(Source: Authors' compilation of maintenance data provided by PKS "Wschod")

Table 5

\begin{tabular}{|c|c|c|c|c|c|c|}
\hline Buses & $\begin{array}{c}\text { Sample size } \\
N \\
{[-]}\end{array}$ & $\begin{array}{c}\text { Scale parameter } \\
\lambda \\
{\left[10^{-4} \mathrm{~km}^{-1}\right]}\end{array}$ & $\begin{array}{c}\text { Level of } \\
\text { significance } \alpha \\
{[-]}\end{array}$ & $\begin{array}{c}\text { Value of } \chi^{2} \\
\text { statistic } \\
{[-]}\end{array}$ & $\begin{array}{c}p \text {-value } \\
{[-]}\end{array}$ & $\begin{array}{c}\text { Goodness of fit } \\
\text { to the exponential } \\
\text { distribution }\end{array}$ \\
\hline Bus I & 20 & 0.517 & 005 & 0.733 & 0.392 & YES \\
\hline Bus II & 18 & 0.419 & 005 & 0.368 & 0.544 & YES \\
\hline Bus III & 19 & 0.415 & 005 & 1.933 & 0.164 & YES \\
\hline Buses I-III & 57 & 0.447 & 005 & 0.192 & 0.979 & YES \\
\hline
\end{tabular}

goodness of fit of distributions of the distance between repairs of the buses to the normal distribution must be rejected in all cases considered.

Considering the fact that the analyzed bus failure data did not include data from the break-in period, the empirical distributions of distance between repairs were tested for goodness of fit to the exponential distribution. Pearson's $\chi^{2}$ goodness of fit test was used to compare empirical distribution functions with exponential distribution functions whose location parameters were zero and scale parameters $\lambda$ were the reciprocals of respective arithmetic means of the sample. The results of the tests are shown in Table 5.

Results of the $\chi^{2}$ test show that at the level of significance $\alpha=0.05$ there is no reason to reject the null hypothesis of goodness of fit of empirical distributions to exponential distributions with the respective scale parameters: $0.517,0.419,0.415,0.447$ $\left(10^{-4} \mathrm{~km}^{-1}\right)$. Because the analyzed results were obtained for the same model of Scania Irizar buses, it can be assumed that in reality the parameters $\lambda$ had the same value. To test this hypothesis, a comparison of the empirical distributions of intervals between successive repairs of buses I, II and III was made using the Kruskal-Wallis test. The calculated value of the test statistic 0.845 corresponds to a $p$-value of 0.655 . This indicates that, at the adopted level of significance $\alpha=0.05$, the hypothesis that the tested empirical distributions of intervals between successive repairs of buses I, II and III come from the same general population cannot be rejected.

\section{Conclusions}

The considerations presented above have a preliminary character. Still, they indicate the direction of further research on failure rates in bus active safety systems. Because the statistical analysis of data from a typical population has shown that exponential distribution can be used to describe the random nature of the distance between successive repairs of safety system failures, future studies should undertake to verify this result. For this purpose, the registered failures should be divided into classes. Also a larger number of buses operating in specific transport systems should be included in the studies and more advanced statistical analyses should be carried out.

The problem of determining the distribution of failures occurring during the operation of a means of transport (which is a subject of interest to the theory of reliability) is closely related to issues of economic efficiency of the operation of transportation systems. An analysis of probability distributions of costs of repairs is carried out in an analogous manner. The financial outlays for maintenance and repair of means of transport are an important parameter in transportation systems [12] and [13]. An analysis of the costs of repairs is a basis for taking decision regarding the disposal of a means of transport, acquisition of a new one, fixing the shipping fee, route assignment, etc. The costs of repairs and maintenance are the basic parameters in stochastic models in operations research, which describe the operating efficiency of transportation systems. Developing such a model dedicated to the assessment of the economic efficiency of public transport systems is the main objective of further research conducted by the Authors of the present article.

\section{Acknowledgement}

The authors wish to thank the Directors of the Motor Transport Company "Wschod" plc in Lublin for providing access to their fleet maintenance data.

\section{References}

[1] Regulation of the Minister of Transport and Maritime Economy of 1 April 1999 on the Technical Conditions of Vehicles and their Required Equipment. Official Law J. of the Republic of Poland, No. 44, pos. 432, of 01 April 1999. Available at: http://isap.sejm. gov.pl 
[2] SZCZURASZEK, T. et al.: Safety of City Traffic. ISBN 978-83-206-1557-4, WKiL, Warszawa 2005

[3] WICHER, J.: Safety of Cars and Traffic. ISBN 83-206-1536-4, WKiL, Warszawa 2004

[4] FIGLUS, T., WILK, A., LISCAK, S., GOZDEK, L.: The Influence of the Road Surface on the Traffic Noise. Transport and Communications, ISSN 1336-7676, No. 2, pp. 473-480, 2012

[5] HLAVNA, V., KUKUCA, P., ISTENIK, R., LABUDA, R., LISCAK, S.: Transport Vehicle-its Engine. ISBN 80-7100-665-3, EDIS Zilina University publisher, Zilina, 2000

[6] VAlaskoVA, M., KRIZANOVA, A.: The Passenger Satisfaction Survey in the Regional Integrated Public Transport System. Promet - Traffic \& Transportation. Scientific J. on Traffic and Transportation Research, ISSN 0353-5320, vol. 20, No. 6, pp. 401-404, 2008

[7] PROCHOWSKI, L., ZUCHOWSKI, A.: Trucks and Buses. ISBN 978-83-206-1815-0, WKiL, Warszawa, 2006

[8] KUCERA, L., LUKAC, M., JURAK, L., BRUMERCIK, F.: Hydromechanical Automatic Transmission. Communications Scientific Letters of the University of Zilina, ISSN 1335-4205. vol. 11, No. 2, pp. 33-35, 2009

[9] SMALKO, Z.: Fundamentals of Technical Operation of Vehicles. ISBN 978-83-870-1293-9, Warsaw University of Technology Publishing House, Warszawa, 1998

[10] LISCAK, S., HOLESA, L., CABAN, J.: Analysis of Impact of Residual Component when Forecasting the Demand of Passengers by Means of Undimensional Time Sequences of Additive Type. Autobusy, Technika, Eksploatacja, Systemy Transportowe, ISSN 1509-5878, No. 3, CD ROM, pp. 1139-1150, 2013

[11] BOBROWSKI, D.: Mathematical Models and Methods of the Theory of Reliability. ISBN 83-204-0721-4, Warsaw, Scientific and Technical Publishers, Warszawa, 1985

[12] COREJOVA, T., ROSTASOVA, M., CHREnKOVA, A., MADUdOVA, E.: Regional Dimensions of Knowledge Processes in the Sector of Transport and Logistics and ICT in the Zilina. Communications - Scientific Letters of the University of Zilina, ISSN 13354205, vol. 15, No. 2, pp. 25-33, 2013

[13] KRIZANOVA, A.: The Current Position and Perspectives of the Integrated Transport Systems in Slovak Republic. Eksploatacja $i$ Niezawodnosc - Maintenance and Reliability, ISSN 1507-2711, No. 4 (40), pp. 25-27, 2008. 